\title{
The Spectrum of Mutations of Homocystinuria in the MENA Region
}

\author{
Duaa W. Al-Sadeq ${ }^{1,2, *}$ and Gheyath K. Nasrallah $1,3, *$ (1) \\ 1 Biomedical Research Center, Qatar University, P.O. Box 2713 Doha, Qatar \\ College of Medicine, Member of QU Health, Qatar University, P.O. Box 2713 Doha, Qatar \\ 3 Department of Biomedical Science, College of Health Sciences, Qatar University, P.O. Box 2713 Doha, Qatar \\ * Correspondence: gheyath.nasrallah@qu.edu.qa (G.K.N.); da1206066@qu.edu.qa (D.W.A-S.); \\ Tel.: +974-4403-6623 (D.W.A-S.); +974-4403-4817 (G.K.N.); Fax: +974-4403-1351 (G.K.N.)
}

Received: 20 February 2020; Accepted: 13 March 2020; Published: 20 March 2020

check for updates

\begin{abstract}
Homocystinuria is an inborn error of metabolism due to the deficiency in cystathionine beta-synthase (CBS) enzyme activity. It leads to the elevation of both homocysteine and methionine levels in the blood and urine. Consequently, this build-up could lead to several complications such as nearsightedness, dislocated eye lenses, a variety of psychiatric and behavioral disorders, as well as vascular system complications. The prevalence of homocystinuria is around 1/200,000 births worldwide. However, its prevalence in the Gulf region, notably Qatar, is exceptionally high and reached 1:1800. To date, more than 191 pathogenic CBS mutations have been documented. The majority of these mutations were identified in Caucasians of European ancestry, whereas only a few mutations from African-Americans or Asians were reported. Approximately $87 \%$ of all CBS mutations are missense and do not target the CBS catalytic site, but rather result in unstable misfolded proteins lacking the normal biological function, designating them for degradation. The early detection of homocystinuria along with low protein and methionine-restricted diet is the best treatment approach for all types of homocystinuria patients. Yet, less than $50 \%$ of affected individuals show a significant reduction in plasma homocysteine levels after treatment. Patients who fail to lower the elevated homocysteine levels, through high protein-restricted diet or by B6 and folic acid supplements, are at higher risk for cardiovascular diseases, neurodegenerative diseases, neural tube defects, and other severe clinical complications. This review aims to examine the mutations spectrum of the CBS gene, the disease management, as well as the current and potential treatment approaches with a greater emphasis on studies reported in the Middle East and North Africa (MENA) region.
\end{abstract}

Keywords: homocystinuria; cystathionine $\beta$-synthase; mutations; MENA

\section{Introduction}

Inborn errors of metabolism represent a large group of genetic disorders that result from an inherited deficiency or lack of proteins involved in metabolic pathways. The majority are defects of single genes that code for enzymes, which catalyze essential biologically and biochemical reactions. Although each specific inborn error of metabolism is rare, taken together, they represent a significant source of congenital disabilities. For instance, it is estimated that a genetically caused inborn error of metabolism occurs in $1 / 2500$ births [1]. A prototypical example of an inborn error of metabolism is homocystinuria due to CBS deficiency [2].

Classical homocystinuria (OMIM 236200) is an autosomal recessive disease and the most common form of homocystinuria worldwide. It is an inborn error of metabolism with high clinical variability resulting in a metabolic disorder due to deficiency in cystathionine beta-synthase CBS enzyme activity (Figure 1). Consequently, an impaired CBS activity leads to the elevation of both the 
methionine and homocysteine levels in the blood and urine, leading to hyperhomocysteinemia, homocystinuria, hypermethioninaemia, and hypocysteinaemia. In healthy adults, the concentration of total homocysteine in plasma ranges from 5 to $15 \mu \mathrm{M}$; however, it reaches $200 \mu \mathrm{M}$ in untreated CBS deficient patients [3]. This build-up could lead to several complications such as nearsightedness and dislocated eye lenses. In addition, the raised homocysteine levels could alter the intracellular signaling and cause endoplasmic reticulum stress with endothelial dysfunction [4,5]. Consequently, leading to thromboembolism, vascular, and other diseases [6]. Clinically, CBS deficient patients may present with intellectual disability, a variety of psychiatric and behavioral disorders, skeletal and ocular abnormalities, vaso-occlusive disease, as well as vascular system complications [7]. Affected babies are healthy at birth, but may exhibit a failure to thrive during infancy and developmental delay during the first years of life. To date, there is no cure for homocystinuria and the available treatments target lowering the homocysteine level through betaine, folic acid, and pyridoxine (vitamin B6) supplements. The main aim is to keep the plasma homocysteine as close to the normal range as possible. However, a considerable fraction of affected patients is nonresponsive to pyridoxine treatment. In addition, a methionine-restricted diet is not optimal, and poor compliance leads to serious complications [8]. Therefore, currently the therapeutic approach for homocystinuria is shifted toward stabilizing and rescuing the protein's native structural conformations through chemical chaperones and proteasome inhibitors. Furthermore, several studies are focusing on other approaches, such as gene and enzyme replacement therapies that will be explained later in Section 6 (Current and potential treatment approaches).

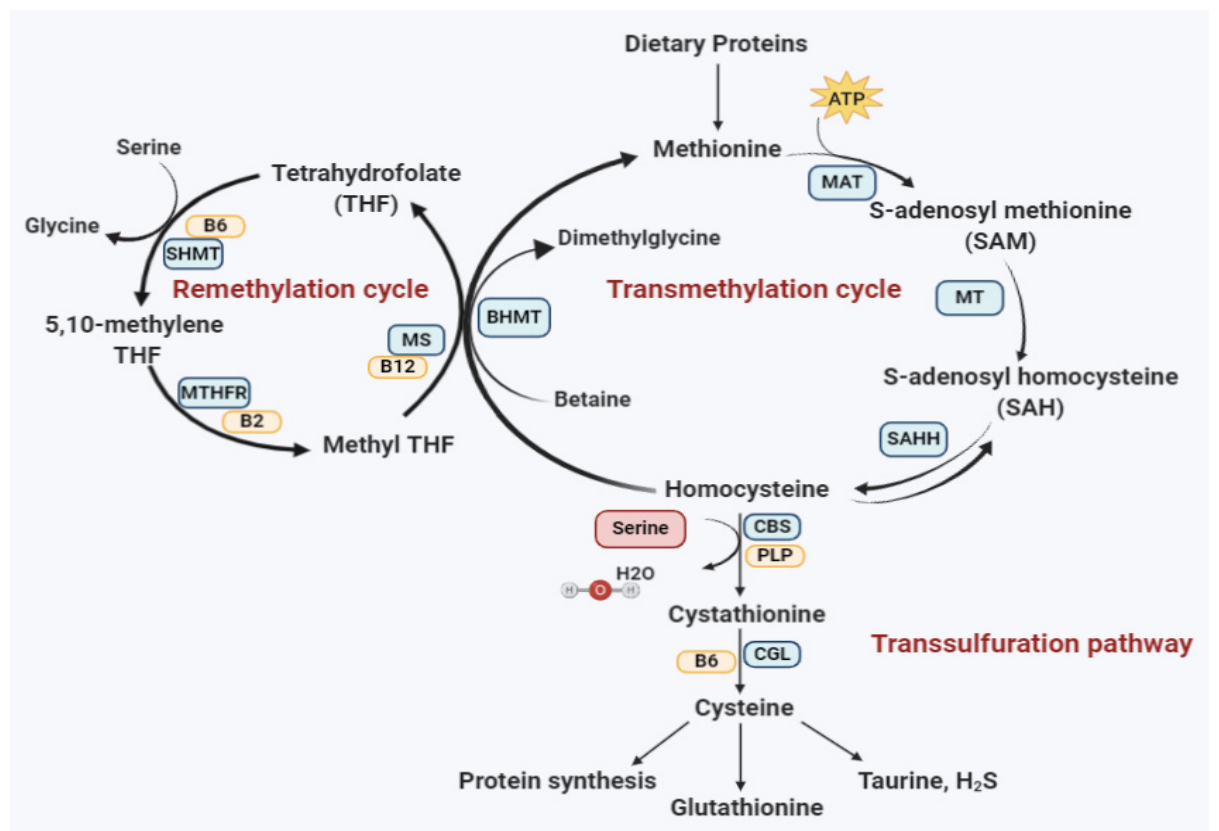

Figure 1. Homocysteine metabolism pathway. Methionine adenosyltransferase (MAT); methyltransferase (MT); S-adenosylhomocysteinase hydrolase (SAHH); betaine-homocysteine methyltransferase (BHMT); pyridoxal-phosphate (PLP); cystathionine gamma-lyase (CGL); methionine synthase (MS); serine-hydroxymethyltransferase (SHMT); methyl-tetrahydrofolate-reductase (MTHFR), hydrogen sulfide $\left(\mathrm{H}_{2} \mathrm{~S}\right)$.

Methionine is an essential sulfur-containing amino acid that is involved in the development and proper mammalian growth. Once the dietary proteins are ingested and methionine enters the cells, methionine adenosyltransferase (MAT) will catalyze the condensation of methionine with ATP and form S-adenosylmethionine (SAM), also known as AdoMet. SAM serves as a crucial methyl donor for various methyltransferase reactions, including hormones biosynthesis and generating S-adenosylhomocysteine (SAH). SAH is then reversibly hydrolyzed into adenosine and homocysteine through the action of 
S-adenosylhomocysteinase hydrolase (SAHH). Homocysteine is a nonproteinogenic toxic intermediary amino acid residing at the intersections of several pathways. It can be remethylated through methionine synthase (MS) or liver-specific betaine-homocysteine methyltransferase (BHMT), which requires betaine as methyl donors. The other route of homocysteine is the transsulfuration pathway, where cystathionine beta-synthase (CBS) irreversibly converts homocysteine to cysteine. It catalyzes the condensation of homocysteine with serine and forms cystathionine, which is subsequently cleaved by cystathionine gammalyase (CGL) into cysteine and 2-oxobutyrate. Cysteine can be further converted to taurine and hydrogen sulfide $\left(\mathrm{H}_{2} \mathrm{~S}\right)$.

Accordingly, the lack of CBS elevates the level of homocysteine and methionine and lowers the concentrations of cystathionine and cysteine in the plasma of homocystinuria patients. It is worth mentioning that both pathways require a particular member of the vitamin B family. For instance, riboflavin (B2) serves as a cofactor for methyl-tetrahydrofolate-reductase, pyridoxine (B6) in serine-hydroxymethyltransferase, CBS and CGL, folic acid (B9) and cobalamin (B12) in methionine synthase. CBS regulates the flow of organic sulfur from methionine to the biosynthesis of all other sulfur-containing compounds such as homocysteine, cysteine, and taurine and their metabolism. Therefore, classical homocystinuria, due to a deficiency in CBS activity, is the most common inborn error of sulfur amino acid metabolism. The prevalence of homocystinuria is around 1/200,000 births worldwide. However, its prevalence in the Gulf region, notably Qatar, is exceptionally high and reached 1:1800 [9].

CBS is a homotetrameric protein with each subunit composed of three structural domains [10,11]: (i) A C-terminal regulatory domain containing the CBS domain tandem and the binding site for the allosteric activator AdoMet (ii) a catalytic core, which is highly conserved and includes the PLP (B6) binding site and; (iii) an N-terminal portion which acts as a heme-binding domain [11,12]. The C-terminal region consists of two CBS domains that are involved in hydrophobic regulatory interactions and could partially shield the active site, thus exhibiting an auto-inhibitory function [13]. SAM binding to the CBS C-terminal domain induces a conformational change that leads to a higher enzymatic activity [14]. This is achieved by eliminating the autoinhibition exerted by the regulatory region, thus, facilitating the access of substrates to the catalytic pocket. In fact, Ereño-Orbea et al. showed that SAM leads to progression of particular CBS mutants toward the activated state. To date, more than 191 pathogenic $C B S$ mutations have been documented. The majority of these mutations were identified in Caucasians of European ancestry, whereas only few mutations from African-Americans or Asians were reported [15]. Approximately $87 \%$ of all CBS mutations are missense and do not target the CBS catalytic site, but rather result in unstable misfolded proteins lacking the normal biological function, designating them for degradation [12]. In addition, a considerable fraction of CBS mutants show impaired response to SAM binding as an allosteric activity modulator and protein stabilizer. This review aims to examine the mutations spectrum of the CBS gene in homocystinuria patients with a greater emphasis on those reported in the Middle East and North Africa (MENA) region.

\section{The most Common CBS Reported Mutations Worldwide}

For the last three decades, CBS inactivating mutations have been extensively studied in the context of causing homocystinuria [16]. Overall, homocystinuria caused by CBS deficiency is considered a relatively rare disease with an incidence rate varying from one in every 200,000 to 335,000 live births. Table 1 summarizes the most common $C B S$ mutations that were reported in different parts of the world. Studies showed that CBS is common in some countries, including Ireland $(1$ in 65,000$)$, Germany (1 in 17,800), Norway (1 in 6400), and reached the highest prevalence in Qatar (1 in 1800) [17]. Homocystinuria is reported as an autosomal recessive disease, where the marriage of two CBS carriers' mutant genes could result in having children with homocystinuria. Furthermore, the high consanguinity rate in the MENA community is considered an important factor that leads to an increase in the prevalence of many metabolic disorders. 
Table 1. Cystathionine beta-synthase (CBS) mutations and clinical phenotypes of homocystinuria reported worldwide.

\begin{tabular}{|c|c|c|c|c|c|c|c|c|}
\hline Country & $\begin{array}{l}\text { Nucleotide } \\
\text { Change }\end{array}$ & Protein Change & Exon & Mutation Type & Consanguinity & $\begin{array}{l}\text { Pathogenicity and most Common } \\
\text { Associated Phenotype Phenotypes }\end{array}$ & $\begin{array}{l}\text { Responsive to } \\
\text { Pyridoxine (Vitamin } \\
\text { B6) Treatment }\end{array}$ & Reference \\
\hline Western Eurasians & c. $833 \mathrm{~T}>\mathrm{C}$ & p.I278T & 8 & Missense & No & $\begin{array}{l}\text { Pathogenic-Ectopia lentis, Marphanoid } \\
\text { feature, mental retardation, idiopathic } \\
\text { infertility, severe vascular complications }\end{array}$ & Responsiveness & [18] \\
\hline $\begin{array}{l}\text { Denmark Norway } \\
\text { Germany } \\
\text { Czech and Slovak } \\
\text { Republics }\end{array}$ & c. $833 \mathrm{~T}>\mathrm{C}$ & p.I278T & 8 & Missense & - & $\begin{array}{l}\text { Pathogenic-Ectopia lentis, Marphanoid } \\
\text { feature, mental retardation, idiopathic } \\
\text { infertility, severe vascular complications }\end{array}$ & Responsiveness & {$[19,20]$} \\
\hline Czech & c. $1105 \mathrm{C}>\mathrm{T}$ & p.R369C & 10 & Missense & - & $\begin{array}{l}\text { Patients do not have any clinical symptoms } \\
\text { at all. The late onset of symptoms, lack of } \\
\text { mental retardation, and connective tissue } \\
\text { involvement }\end{array}$ & Responsiveness & [21] \\
\hline \multirow[t]{2}{*}{ Slovakia } & $526 \mathrm{G}>\mathrm{A}$ & p.E176K & 4 & Missense & No & $\begin{array}{l}\text { Conflicting interpretations of pathogenicity. } \\
\text { Thoracic aortic aneurysm and aortic } \\
\text { dissection. Cardiovascular phenotype }\end{array}$ & Nonresponsiveness & \multirow[t]{2}{*}{ [22] } \\
\hline & $1226 \mathrm{G}>\mathrm{A}$ & p.W409X & 12 & Nonsense & No & - & Nonresponsiveness & \\
\hline \multirow[t]{3}{*}{ Netherland } & c. $833 \mathrm{~T}>\mathrm{C}$ & p.I278T & 8 & Missense & No & $\begin{array}{l}\text { Pathogenic-Ectopia lentis, Marphanoid } \\
\text { feature, mental retardation, idiopathic } \\
\text { infertility, severe vascular complications }\end{array}$ & Responsiveness & {$[12,19]$} \\
\hline & c.539 T>C & p.V180A & 5 & Missense & No & - & - & \multirow{2}{*}{ [12] } \\
\hline & c. $1330 \mathrm{G}>\mathrm{A}$ & p.D444N & 12 & Missense & No & Mild & - & \\
\hline \multirow{2}{*}{ Ireland } & c. $919 \mathrm{G}>\mathrm{A}$ & p.G307S & 8 & Missense & - & Pathogenic-Cardiovascular phenotype & Nonresponsiveness & [23-25] \\
\hline & c. $306 \mathrm{G}>\mathrm{C}$ & p.K102N & 2 & Missense & No & $\begin{array}{l}\text { Likely pathogenic-Neurogenic bladder or } \\
\text { bowel signs, developmental delay, mental } \\
\text { retardation }\end{array}$ & Responsiveness & [26] \\
\hline \multirow{4}{*}{ Italy } & c. $146 \mathrm{C}>\mathrm{T}$ & p.P49L & 1 & Missense & No & Pathogenic, VUS Cardiovascular phenotype & Responsiveness & [27] \\
\hline & c. $172 \mathrm{C}>\mathrm{T}$ & p.R58W & 1 & Missense & No & $\begin{array}{l}\text { Mild mental retardation with EEG } \\
\text { anomalies, osteoporosis, malar flush, and } \\
\text { ultrasound evidence of arterial disease }\end{array}$ & Nonresponsiveness & [28] \\
\hline & c. $262 \mathrm{C}>\mathrm{T}$ & p.P88S & 2 & Missense & - & $\begin{array}{l}\text { Pathogenic-Zonular pulverulent cataract } \\
\text { phenotype }\end{array}$ & - & [29] \\
\hline & c. $469 \mathrm{G}<\mathrm{C}$ & p.A157P & 4 & Missense & No & $\begin{array}{l}\text { Pathogenic-Pectus escavatum, Tricuspid } \\
\text { valve prolapse, Kyphoscoliosis, } \\
\text { Iridodonesis, Mild elbow valgus }\end{array}$ & - & [30] \\
\hline
\end{tabular}


Table 1. Cont

\begin{tabular}{|c|c|c|c|c|c|c|c|c|}
\hline Country & $\begin{array}{l}\text { Nucleotide } \\
\text { Change }\end{array}$ & Protein Change & Exon & Mutation Type & Consanguinity & $\begin{array}{l}\text { Pathogenicity and most Common } \\
\text { Associated Phenotype Phenotypes }\end{array}$ & $\begin{array}{l}\text { Responsive to } \\
\text { Pyridoxine (Vitamin } \\
\text { B6) Treatment }\end{array}$ & Reference \\
\hline \multirow{3}{*}{ Spain } & c. $869 \mathrm{C}>\mathrm{T}$ & p.P290L & 8 & Missense & No & Hermansky Pudlak syndrome 2 & Responsiveness & [29] \\
\hline & c. $572 \mathrm{C}>\mathrm{T}$ & p.T191M & 5 & Missense & No & Pathogenic & Nonresponsiveness & [31] \\
\hline & c. $833 \mathrm{~T}<\mathrm{G}$ & p.I278S & 8 & Missense & No & Pathogenic & Responsiveness & [32] \\
\hline Portugal & c. $572 \mathrm{C}>\mathrm{T}$ & p.T191M & 5 & Missense & No & Pathogenic & Nonresponsiveness & [31] \\
\hline Venezuela & c.700G >A & p.D234N & 8 & Missense & Yes & $\begin{array}{l}\text { Pathogenic-Skeletal and ocular } \\
\text { abnormalities }\end{array}$ & Nonresponsiveness & [33] \\
\hline \multirow{2}{*}{ France } & $1150 \mathrm{~A}>\mathrm{G}$ & p.K384E & 11 & Missense & No & Pathogenic & Responsiveness & \multirow{2}{*}{ [34] } \\
\hline & $1616 \mathrm{~T}>\mathrm{C}$ & p.L539S & 16 & Missense & No & Pathogenic & Responsiveness & \\
\hline \multirow{4}{*}{ UK } & c. $374 \mathrm{G}>\mathrm{A}$ & p.R125Q & 3 & Missense & No & $\begin{array}{c}\text { Pathogenic } \\
\text { Cardiovascular phenotype }\end{array}$ & - & [35] \\
\hline & c. $430 \mathrm{G}>\mathrm{A}$ & p.E144K & 3 & Missense & No & $\begin{array}{c}\text { Pathogenic } \\
\text { Cardiovascular phenotype }\end{array}$ & - & [35] \\
\hline & c. $833 \mathrm{~T}>\mathrm{C}$ & p.I278T & 8 & Missense & No & $\begin{array}{l}\text { Pathogenic-Ectopia lentis, Marphanoid } \\
\text { feature, mental retardation, idiopathic } \\
\text { infertility, severe vascular complications }\end{array}$ & Responsiveness & [35] \\
\hline & c. $919 \mathrm{G}>\mathrm{A}$ & p.G307S & 8 & Missense & No & Pathogenic-Cardiovascular phenotype & Nonresponsiveness & {$[25,35]$} \\
\hline \multirow{8}{*}{ USA } & c. $341 \mathrm{C}>\mathrm{T}$ & p.A114V & 3 & Missense & No & - & - & [35] \\
\hline & c. $374 \mathrm{G}>\mathrm{A}$ & p.R125Q & 3 & Missense & No & Pathogenic-Cardiovascular phenotype & Nonresponsiveness & {$[35,36]$} \\
\hline & c. $785 \mathrm{C}>\mathrm{T}$ & p.T262M & 7 & Missense & No & $\begin{array}{l}\text { Pathogenic-Thromboembolic episodes, } \\
\text { mental retardation }\end{array}$ & Nonresponsiveness & {$[35,36]$} \\
\hline & c.797G $>\mathrm{A}$ & p.R266K & 7 & Missense & No & - & Responsiveness & [35] \\
\hline & c. $833 \mathrm{~T}>\mathrm{C}$ & p.I278T & 8 & Missense & No & Pathogenic-Severe vascular complications & Responsiveness & [35] \\
\hline & c. $919 \mathrm{G}>\mathrm{A}$ & p.G307S & 8 & Missense & No & Pathogenic-Cardiovascular phenotype & Nonresponsiveness & {$[25,35]$} \\
\hline & g. $13217 \mathrm{~A}>\mathrm{C}$ & (del ex 12) & Intron 11 & Deletion & No & - & - & [35] \\
\hline & c.1330G >A & p.D444N & 12 & Missense & No & $\begin{array}{l}\text { Pathogenic-Psychomotoric retardation and } \\
\text { marfanoid features }\end{array}$ & $\begin{array}{c}\text { Partially } \\
\text { pyridoxine-responsive }\end{array}$ & {$[35,37]$} \\
\hline India & c.518delTGA & p.M173del & 4 & Deletion & No & Pathogenic & - & [32] \\
\hline \multirow{3}{*}{ Argentina } & c. $676 \mathrm{G}<\mathrm{A}$ & p.A226T & 6 & Missense & No & Mild-Hypertrophic cardiomyopathy & Responsiveness & {$[25,32]$} \\
\hline & c. $962 \mathrm{~A}<\mathrm{T}$ & p.D321V & 9 & Missense & No & Pathogenic-Crouzon syndrome & - & {$[32,38]$} \\
\hline & c. $1336 \mathrm{G}<\mathrm{T}$ & p. A446S & 12 & Missense & No & Mild-lens dislocation & Responsiveness & [32] \\
\hline Australia & c. $833 \mathrm{~T}>\mathrm{C}$ & p.I278T & 8 & Missense & No & $\begin{array}{l}\text { Pathogenic-Ectopia lentis, Marphanoid } \\
\text { feature, mental retardation, idiopathic } \\
\text { infertility, severe vascular complications }\end{array}$ & Responsiveness & [39] \\
\hline
\end{tabular}


The CBS gene is located on the long arm of chromosome 21 with 191 variants having been described [40] (Figure 2). The most frequent pathogenic and reported mutations in different countries around the world are p.G307S (31\%), and p.I278T (24\%) [41,42]. The p.G307S mutation is the most prevalent CBS deficiency mutation in Ireland and Australia [6,23]. It is located on exon 8 of $C B S$ gene, where guanine at position 919 is replaced by adenine nucleotide (c.919G>A). This change leads to glycine to serine substitution at position 307. Homozygous patients are severely affected with minimal to nonresponse to pyridoxine (B6) treatment $[28,43]$. Studies showed that p.G307S mutation is also frequently detected in homocystinuria patients of Celtic descent [43]. Using molecular dynamic simulations, a study showed that p.G307S mutation impaired the catalytic function of the CBS enzyme by preventing the tyrosine residue at position 308 to assume the proper conformational folding. This state is required for forming the pyridoxal-cystathionine intermediate. Additionally, results showed CBS with p.G307S mutation is stable, but inactive, and hence does not respond either to chaperone-based therapy nor pyridoxine treatment [24].

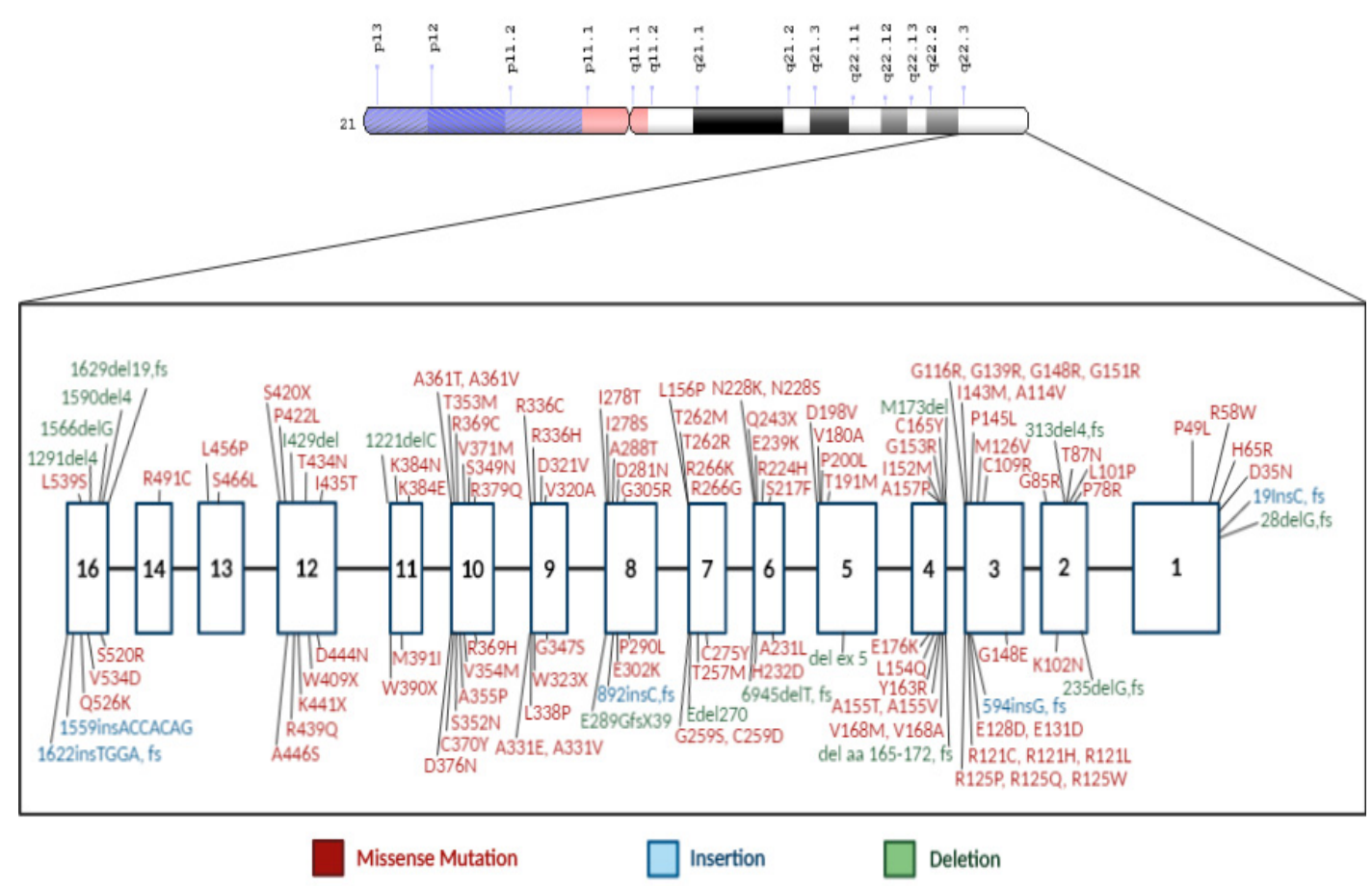

Figure 2. $C B S$ gene structure with associated mutations. Exons are represented by white numbered boxes and the $C B S$ variants are color coded by mutation type.

Similarly, the p.I278T mutation affects the catalytic domain of the CBS enzyme [16]. Yet, confers responsiveness to pyridoxine treatment [6]. It is considered the most prevalent mutation worldwide, particularly in homocystinuria patients of nonCeltic descent [43]. The p.1278T mutation was first identified in a pyridoxine-responsive patient with mild clinical manifestation [44]. This mutation results from incorrect excision of a 68-bp repeat polymorphism within the CBS gene [45]. Consequently, it leads to the substitution of thymine with a cytosine at position 833 (c.883T>C) of exon 8 . This change leads to isoleucine to threonine substitution at position 278 . The pathogenicity of p.I278T CBS mutation was shown to be due to the lack of catalytic activity in a bacterial and yeast expression system. For instance, using the yeast S. cerevisiae as an in vitro model showed that p.I278T has only $2.4 \%$ of the human wildtype CBS enzymatic activity and failed to complement the growth phenotype [46]. Consequently, patients with p.I278T usually had vascular and connective tissue defects [47]. Other clinical complications of defective CBS enzyme include dislocation of the ocular lenses (ectopia lentis), mental retardation, osteoporosis, and thromboembolism. 


\section{The Prevalence of CBS and Associated Mutations in the MENA Region}

The establishment of newborn screening programs has successfully decreased the prevalence of homocystinuria and other aminoacidopathies. Yet, the majority of these disorders arise due to consanguineous marriages [48]. The consanguinity rate reached $40 \%$ among first cousins in the Middle East and up to $60 \%$ in intermarriages between relatives. Therefore, the incidence of genetic disorders, including homocystinuria, has increased. To date, scarce studies reported the incidence rate of CBS in the MENA region. For instance, the reported incidence in Oman is one in approximately 128,200 births [49], while in Saudi Arabia, the incidence of homocystinuria is two in 100,000 live births [50]. Additionally, in a Kuwait-based study, the frequency of $C B S$ mutation among intellectually disabled patients was $0.23 \%$ [51].

In Qatar, the homozygous mutation c.1006C $>\mathrm{T}$ (p.R336C), which is found on exon 9 of the $C B S$ gene (Figure 2), a missense mutation in which arginine is replaced by cysteine, consequently resulting in a severe vitamin B6 nonresponsive phenotype [9]. The prevalence of this unique mutation in Qatar is approximately 1:1800 births, where $\sim 6 \%$ of the population has a heterozygous p.R336C mutation with an allele frequency of $1 \%$ [52]. The p.R336C mutation was first reported in a patient of English descent [28]. Subsequently, it was observed in Australia [53], the Iberian peninsula [54], and recently in Korea [55]. The in vitro expression studies, as well as the enzymatic measurements, along with the clinical symptoms of the patients suffering from this mutation, showed that the mutation eliminated the CBS enzymatic activity. The p.R336C mutation appears to be recurrent in different independent populations. Thus, the correlation between this mutation in the Qatari population and other populations could not be established. Treating the Qatari homocystinuria patients with traditional therapy has been very challenging because the strict low protein content diet is difficult to maintain, and the p.R336C mutation is pyridoxine nonresponsive. Therefore, this disease imposes a financial and clinical burden on the population in Qatar that necessitates an urgent need for the development of an adequate therapy [52,56].

On the other hand, one Qatari patient had a homozygous mutation c.700G>A (p.D234N), which was previously described in Puerto Rican [12] and Venezuelan patients [57]. Similar to c.1006C $>$ T mutation, this mutation includes a hypermutable $\mathrm{CpG}$ dinucleotide (transition from guanine to adenine) [58]. According to El-said et al., this mutation has a high chance of recurrence in the Qatari population [59]. However, according to the clinical observation and the genotyping of all Qatari patients suffering from homocystinuria predict the absence of CBS enzymatic activity and nonresponsiveness to vitamin B6 supplements [59]. Although homocystinuria is considered the most prevalent monogenic disease in Qatar, early detection has improved the prevention of some complications, including mental retardation, ectopia lentis, and thromboembolic events [60].

In Saudi Arabia, patients suffering from homocystinuria expressed the cardinal biochemical features of homocystinuria. In addition, most of the clinical manifestations reported due to homocystinuria in the Saudi Arabian cohort were related to the ophthalmological, musculoskeletal, vascular, and nervous systems complications [7,27,61]. For instance, some Saudi patients, who suffered from white matter abnormalities, were also reported with homocystinuria. However, Zaidi et al., reported a case of Legg-Calv'e-Perthes disease, a previously unknown complication in homocystinuria, which was observed in one patient suffering from a novel p.W323X mutation in the CBS gene [62]. Zaidi et al., explained the occurrence of Legg-Calv'e-Perthes disease as vascular thromboembolism due to the persistently elevated homocysteine leading to vascular necrosis of the femoral head in their patients. This novel mutation is considered the predominant mutation in Saudi Arabia and was reported in 10 Saudi families. This could be due to the high consanguinity marriage causing homozygosity of the recessive alleles and the expression of disease phenotype in patients. Similarly, two recurrent mutations, c.457G $>$ A (p.G153R) and c.1006C $>$ T (p.A336C), were reported in two Saudi families and described previously $[28,53,63]$.

In Palestinian Arab homocystinuria patients, six different $C B S$ mutations, c.304A $>C$, c.833T $>C$, c.785C > G, g.1627del19, IVS17 (g18327del 5), and IVS4 (g6643del 29), have been reported in this highly 
inbred population [64]. These mutations were novel and were not reported in the neighboring regions. However, patients living in the same villages carry the same genetic alterations, thus indicating a founder effect. Despite the adjacent geographic region of Palestine, Saudi, Palestinian Arabs have a different spectrum of the $C B S$ gene mutations. The narrow geographic spread of these mutations suggests that they arose over the past few generations [64].

In Sudan, a CBS mutation c.770C>T (p.T257M or pThr257Met) was reported. Interestingly, the same mutation was also reported in Spanish and Italian families $(15,17)$. The pThr257Met mutation was shown to have $<1 \%$ of the CBS enzyme activity and conferred nonresponsiveness to pyridoxine treatment. Table 2 summarizes the identified CBS mutations that were reported in different countries of the MENA region.

\section{Recent Novel CBS Mutations}

Recently, two novel mutations, a missense change (c.467T>C; p.L156P) and an in-frame deletion (c.808_810del; p.E270del) were reported in Pakistani children [65]. The mutations were identified using Sanger sequencing and resulted in hyperhomocysteinemia and lens dislocation in three patients from different families. In addition, eight novel mutations in $C B S$ were identified in Chinese patients with classical homocystinuria. None of these missense mutations were reported in other regions previously. Moreover, the effect of these mutations on CBS gene expression, CBS protein expression, stability, and activity is not investigated yet. However, Li et al., with the use of the PolyPhen-2 prediction software, indicated that the p.T236A and p.L230G are probably damaging while the p.L72I is a benign mutation. On the other hand, the SIFT prediction software indicated that the p.T236A and p.L230G are damaging, while the p.L72I is a tolerated mutation (17). Similarly, a total of 35 samples were obtained from Brazilian patients with a biochemically confirmed diagnosis of classical homocystinuria [42]. Eight novel mutations [c.2T>C, c.209+1delG, c.284T>C, c.329A>T, c.444delG, c.864_868delGAG, c.989_991delAGG, and c.1223+5G $>$ T] were found. It is worth mentioning that there was high variability in the genotypes, and most of the patients in this study were pyridoxine nonresponsive. Generally, the treatment of homocystinuria patients with varying missense mutations is based on a combined high-dose of cofactors of homocysteine metabolism and a life-long methionine-restricted diet. Yet, less than $50 \%$ of affected individuals show a significant reduction in plasma homocysteine levels after treatment $[7,66]$.

\section{Clinical Diagnosis and Disease Detection}

Clinically, patients with classic homocystinuria exhibit numerous manifestations during infancy because homocysteine disrupts the development of many organ systems. These include Marfanoid habitus, pectus exavatum (curved-in sternum), pectus carinatum (protruding sternum), genu valgum, where knees are angled toward each other, and many other skeletal deformities [67,68]. In addition, ectopia lentis (dislocation of the lens) can lead to nearsightedness and blurred vision. Homocystinuria was first discovered in 1962 in Northern Ireland, where the patients had mental retardation [69]. Shortly after that, CBS enzyme deficiency was demonstrated as the causative factor for this abnormality [70]. Significant progress has been achieved in diagnosing homocystinuria since the time of its discovery. 
Table 2. CBS mutations and clinical phenotypes of homocystinuria in Arab countries.

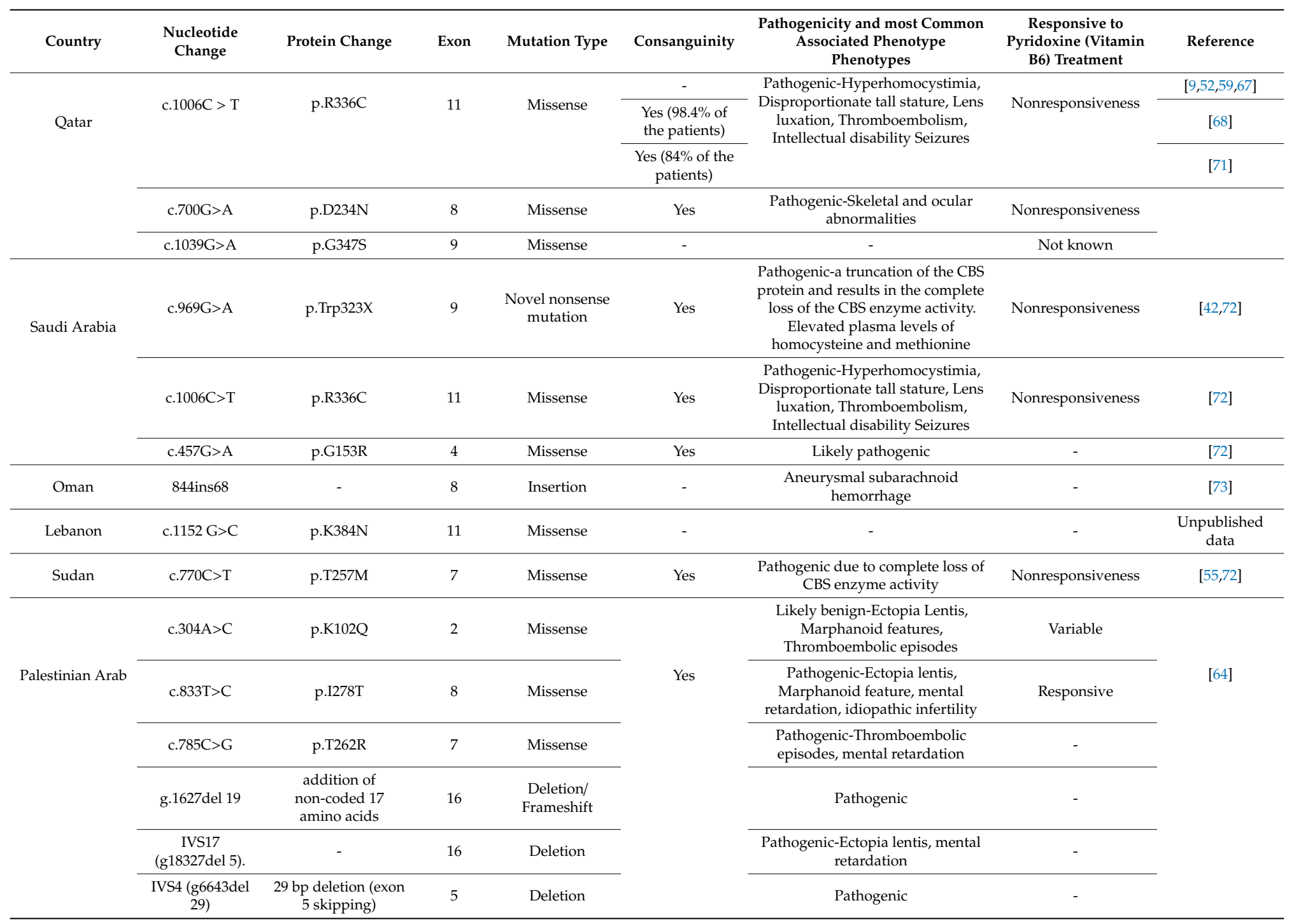


Table 2. Cont.

\begin{tabular}{|c|c|c|c|c|c|c|c|c|}
\hline Country & $\begin{array}{l}\text { Nucleotide } \\
\text { Change }\end{array}$ & Protein Change & Exon & Mutation Type & Consanguinity & $\begin{array}{c}\text { Pathogenicity and most Common } \\
\text { Associated Phenotype } \\
\text { Phenotypes }\end{array}$ & $\begin{array}{c}\text { Responsive to } \\
\text { Pyridoxine (Vitamin } \\
\text { B6) Treatment }\end{array}$ & Reference \\
\hline \multirow[t]{2}{*}{ Pakistan } & c. $467 \mathrm{~T}>\mathrm{C}$ & p.L156P & 7 & Missense & Yes & $\begin{array}{l}\text { Pathogenic-Developmental and } \\
\text { Neurological problems. Myopia } \\
\text { and lens dislocation }\end{array}$ & - & \multirow[t]{2}{*}{ [65] } \\
\hline & c.808_810del & p.E270del & 10 & $\begin{array}{l}\text { In-frame } \\
\text { deletion }\end{array}$ & Yes & $\begin{array}{c}\text { Pathogenic } \\
\text { Developmental and Neurological } \\
\text { problems. Glaucoma and } \\
\text { subluxated lens. }\end{array}$ & - & \\
\hline
\end{tabular}


Although the management and clinical diagnosis of homocystinuria could differ from country to country, this disorder is mostly diagnosed based on the patient clinical features and routine metabolic testing. The analysis of plasma and urine amino acid will show a frequent elevation of both methionine (>50 $\mu \mathrm{mol} / \mathrm{L}$ ) and homocysteine (>100 $\mu \mathrm{mol} / \mathrm{L})$. Some Arab countries have implemented the utilization of several molecular diagnostic techniques, including mass spectrometry (MS), high-pressure liquid phase chromatography (HPLC), and sequencing techniques such as Sanger and next-generation sequencing [74]. In addition, molecular genetic testing and neonatal screening programs have been incorporated in the disease screening system as early intervention could facilitate effective treatment. Yet, this genetic monitoring requires high-throughput, reliable, and rapid methods to extract DNA and subsequently analyze the mutations, which may not be universally available and could be challenging to implement [52]. Additionally, some technologies are currently emerging in rapid metabolite-based disease biomarker screening. For instance, a recent study identified paper spray ionization mass spectrometry (PSI-MS) for analyzing metabolic biomarkers associated with children disorder [75]. As mass spectrometry is a recognized gold standard technique for an inborn error of metabolism study, PSI-MS shows great potential for point-of-care clinical applications. Additionally, PSI-MS could be a great tool for early stage rapid biomarker discovery for Homocystinuria. In addition, other assays depend on measuring the CBS activity through a fluorescent probe. For instance, the assay utilizes homocysteine and cysteine as a substrate to produce hydrogen sulfide. The latter will react with a probe containing azido-functional group and consequently yielding a fluorescent amino group. Previously, an elevated level of methionine was detected through screening of homocystinuria biochemical metabolites. However, this method had poor sensitivity. In addition, it was technically difficult to quantify homocysteine in dried blood spots (DBS). Due to the high prevalence of homocystinuria and, because early detection could significantly benefit children, a dual strategy screening has been developed in Qatar to screen all newborns with homocystinuria [58]. The national biochemical and molecular newborn screening (NBS) program has been established in Qatar in 2006, which includes both biochemical and molecular screening approaches. These include combining HPLC with tandem mass spectrometry to quantify the total homocysteine in DBS. Additionally, rapid high-throughput genetic screening has been introduced to detect $C B S$ gene mutations that are identified in Qatari population including p.R336C and p.D234N. This was achieved by utilizing an automated 96-well plate DNA extraction method followed by individual PCR-based fluorogenic TaqMan probe assays [58].

Apart from the disease management and complications that may arise during the patient's lifespan, parents should be aware that there is a $25 \%$ chance of recurrence risk in a subsequent pregnancy. Additionally, there is an increased likelihood that a child with homocystinuria may have siblings who are potential carriers [41]. Therefore, genetic counseling is recommended for prospective parents, especially those with a history of homocystinuria in the family. Moreover, prenatal diagnosis can be implemented and achieved through culturing the chorionic villi and amniotic cells to test for the presence of CBS enzyme [76].

\section{Current and Potential Treatment Approaches}

The early detection of homocystinuria along low protein and methionine restricted diet is the best treatment approach for all types of homocystinuria patients [68]. Referring to the homocystinuria metabolism pathway (Figure 1), the administration of folic acid and pyridoxine is also considered as an effective therapy, especially in pyridoxine-responsive patients, as these supplements have shown to enhance the CBS enzyme residual activity in more than half of the patients [77]. Yet, they were not effective in patients with B6 nonresponsive mutations such as the p.R336C [58]. Although significant advances were made toward curing homocystinuria and protein misfolding, yet, there are no curative treatments for this disease. Protein misfolding and its accumulation are the upstream events in the pathological cascade. Thus, stabilizing and rescuing the protein's native structural conformations is a targeted therapeutic approach. 
Recently, chaperones have been recognized as effective molecules in reducing the accumulation of misfolded proteins. Accordingly, minimizing their downstream pathological consequences. Several chemical chaperones are receiving attention as possible treatments for many misfolded protein mutations. For instance, the administration of $2 \%$ of the trehalose solution orally increased the stability of the huntingtin containing protein and improved the motor dysfunction in a mouse model [78]. Randomized clinical trials proved that an FDA-approved Buphenyl, used for treating urea cycle disorders, causes substantial stimulation of chloride transport in homozygous patients for F508 CFTR. Thus, it is a viable therapeutic approach for cystic fibrosis patients [79].

In regards to CBS, Kopecka et al. studied in vitro the effect of selected chaperones including $\delta$-aminolevulinic acid ( $\delta$-ALA) and three osmolytes (taurine, betaine, and glycerol) on 27 different CBS mutants. Of which, 14 mutants responded by at least $30 \%$ increase in the enzymatic activity, and four mutants showed an increased formation of CBS tetramers, without an increase in the CBS activity [80]. For instance, PBA and TUDCA are FDA approved chemical chaperones used for urea cycle disorders and biliary cirrhosis treatment, respectively [81]. Furthermore, studies showed that PBA attenuates the endoplasmic reticulum (ER) stress and acts as an ammonia scavenger in urea cycle disorders [82]. Similarly, TUDCA has been shown to mitigate the ER stress and have an anti-apoptotic and antioxidant activity [83].

Another potential chemical chaperone is betaine, which uses an alternative pathway to convert homocysteine into methionine, and was reported to be effective in pyridoxine nonresponsive patients [84]. In an attempt to rescue the functional defect of the p.R336C CBS mutation, a study was conducted using knock-in p.R336C mutation in HEK293T cell line [9]. Cells were treated with different types of chaperones (betaine, glycerol, sorbitol, and proline) at different concentrations. Interestingly, betaine was able to restore the structural defect of the p.R336C protein in vivo, but not the activity of the p.R336C mutation. Various treatment approaches, such as chemical chaperones [9], CBS enzyme replacement therapy, and gene therapy [85] could be promising alternative treatments for homocystinuria patients. Additional treatment strategies including the administration of proteasome inhibitors or protein stabilizing drugs to prevent early degradation of mutated CBS protein. For example, a recent report showed that proteasome inhibitors rescued the phenotype in p.I278T and p.S466L mutant mice [86]. Furthermore, it was documented that bortezomib was able to restore both the growth and CBS activity in p.I278T mutant yeast and mice [87]. Other potential chemical chaperones include tauroursodeoxycholic acid (TUDCA), sodium 4-phenylbutyrate (PBA), urea derivatives chemical chaperones such as trimethylamine oxide (TMAO), amino acid derivatives chemical chaperones such as glycine, polyols chemical chaperones such as glycerol and sorbitol, mannitol, maltose, phenyl butyric acid. Additionally, the use of aminothiols, such as cysteamine, holds potential clinical promise to target arginine to cysteine mutations of different genetic disorders [88]. It is worth mentioning that SAM analogs are also considered pharmacological chaperones and kinetic stabilizers that could prevent the misfolding and rapid degradation of mutant CBS protein [89]. Studies demonstrated that CBS tetramer is stabilized by SAM binding to a site different from the allosteric site responsible for activation, and presented natural analogues that could stabilize CBS tetramer without interfering with allosteric activation. Thus, rescuing the CBS activity in homocystinuria patients [89,90]. Yet, some mutations, such as R125Q, E176K, P422L, and S466L, are SAM-nonresponsive mutants [90].

Shifting to in vivo models, a study previously described the development of a genetically engineered mouse that expresses the p.R336C human CBS protein as its only source of CBS (Tg-R336C Cbs-/-) [91]. As expected, these mice have extreme elevation in both serum total homocystinuria and liver total homocystinuria compared to control transgenic mice. However, the administration of bortezomib showed a complete rescue of CBS activity in these mice. The creation of such an in vivo system to modulate plasma homocysteine would be useful in the study of homocysteine-related diseases and finding novel therapeutic approaches for CBS deficiency. For instance, a study used a minicircle-based naked DNA gene therapy technique to treat CBS deficient mice (Tg-I278T Cbs-/-) [92]. Following the injection of mice with the DNA-minicircle vector, results showed a significant decrease 
in serum total homocysteine level with a 34-fold increase in liver CBS activity. Therefore, the study suggested that minicircle-based gene therapy could be a potential treatment for CBS deficiency. Another promising approach is the enzyme replacement therapy. It involves intravenous infusions to correct the deficiency or absence of an enzyme in the body. This approach was reported to be successful in lysosomal storage diseases such as Gaucher disease, Fabry disease, as well as severe combined immunodeficiency [86]. However, the use of enzyme replacement therapy to treat homocystinuria due to CBS deficiency is not well addressed. Therefore, a recent study aimed to address the core enzyme deficiency through the long-term administration of PEG-CBS [8]. Results showed that enzyme replacement therapy significantly reduced the plasma homocysteine concentration and normalized plasma cysteine for up to nine months of treatment. The metabolic and biochemical balance was restored and improved in the kidney, liver, and brain of the CBS deficient mice (Tg-I278T Cbs-/-). Therefore, enzyme replacement therapy has the potential to successfully correct the clinical manifestations in homocystinuria patients and improve their life quality.

\section{Conclusions}

Homocystinuria is a monogenic disease caused by a deficiency in the activity of the CBS enzyme. This study highlighted the necessity for further epidemiological studies in Arab countries, especially in areas with high prevalence of consanguineous marriage. High consanguinity rate in the MENA community is considered a factor that could also increase the prevalence of many metabolic disorders including homocystinuria. Therefore, public health strategies should be implemented to increase public understanding and awareness of the consequent genetic risks of consanguineous marriages. In addition, screening programs should be applied in all Arab nations to facilitate its early detection and consequent treatment. Although significant advances have been made toward curing homocystinuria, yet, there are no curative treatments for this disease. Chemical chaperones and protein stabilizers are considered potential therapeutic approaches for stabilizing and rescuing the protein's native conformations. Thus, restoring the CBS enzyme activity.

Author Contributions: Conceptualization, D.W.A.-S. and G.K.N.; Data curation, D.W.A.-S. and G.K.N.; Writing-original draft preparation, D.W.A.-S.; Writing—review and editing, G.K.N.; Visualization, D.W.A.-S. and G.K.N.; supervision, G.K.N.; Project administration, G.K.N.; Funding acquisition, G.K.N. All authors have read and agreed to the published version of the manuscript.

Funding: The IRCC-2019-007 grant was given to G.K.N. and GSRA6-1-0413-19013 grant was given to D.W.A. and G.K.N. We extend our gratitude to the Qatar National Library (QNL), a member of Qatar Foundation, for sponsoring the publication fees of this article.

Acknowledgments: We would like to thank Prasanna Kolatkar and Nadin Younes for reviewing this article.

Conflicts of Interest: The authors declare no conflict of interest.

\section{References}

1. Applegarth, D.A.; Toone, J.R. Incidence of inborn errors of metabolism in British Columbia, 1969-1996. Pediatrics 2000, 105, e10. [CrossRef] [PubMed]

2. Mudd, S.H.; Levy, H.L.; Kraus, J.P. The Online Metabolic and Molecular Bases of Inherited Disease. Scriver CR 2001, 2007-2056.

3. Kruger, W. Cystathionine $\beta$-synthase deficiency in Georgia (USA): Correlation of clinical and biochemical phenotype with genotype. Hum. Mutat. 2003, 22, 434-441. [CrossRef] [PubMed]

4. Lai, W.K.C.; Kan, M.Y. Homocysteine-induced endothelial dysfunction. Ann. Nutr. Metab. 2015, 67, 1-12. [CrossRef] [PubMed]

5. Schienle, H.W. Thrombomodulin and ristocetincofactor in homocystinuria: A study in two siblings. Thromb. Res. 1995, 77, 79-86. [CrossRef]

6. Scriver, C.R. The Metabolic \& Molecular Bases of Inherited Disease; McGraw-Hill: New York, NY, USA, 2001.

7. Mudd, S.H. The natural history of homocystinuria due to cystathionine $\beta$-synthase deficiency. Am. J. Hum. Genet. 1985, 37, 1. 
8. Majtan, T. Enzyme replacement therapy ameliorates multiple symptoms of murine homocystinuria. Mol. Ther. 2018, 26, 834-844. [CrossRef]

9. Ismail, H.M. In silico and in vivo models for Qatari-specific classical homocystinuria as basis for development of novel therapies. Hum. Mutat. 2019, 40, 230-240. [CrossRef]

10. Kery, V.; Poneleit, L.; Kraus, J.P. Trypsin cleavage of human cystathionine $\beta$-synthase into an evolutionarily conserved active core: Structural and functional consequences. Arch. Biochem. Biophys. 1998, 355, 222-232. [CrossRef]

11. Meier, M. Structure of human cystathionine $\beta$-synthase: A unique pyridoxal 5 '-phosphate-dependent heme protein. EMBO J. 2001, 20, 3910-3916. [CrossRef]

12. Kraus, J.P. Cystathionine ${ }^{2}$-synthase mutations in homocystinuria. Hum. Mutat. 1999, 13, 362. [CrossRef]

13. Majtan, T. Active cystathionine $\beta$-synthase can be expressed in heme-free systems in the presence of metal-substituted porphyrins or a chemical chaperone. J. Biol. Chem. 2008, 283, 34588-34595. [CrossRef]

14. Ereño-Orbea, J. Structural insight into the molecular mechanism of allosteric activation of human cystathionine $\beta$-synthase by S-adenosylmethionine. Proc. Natl. Acad. Sci. USA 2014, 111, E3845-E3852. [CrossRef] [PubMed]

15. Ignoul, S.; Eggermont, J. CBS domains: Structure, function, and pathology in human proteins. Am. J. Physiol. Cell Physiol. 2005, 289, C1369-C1378. [CrossRef] [PubMed]

16. Majtan, T. Potential pharmacological chaperones for cystathionine beta-synthase-deficient homocystinuria. In Targeting Trafficking in Drug Development; Springer: Berlin, Germany, 2017; pp. 345-383.

17. Shawky, R.M. Profile of genetic disorders prevalent in northeast region of Cairo, Egypt. Egypt. J. Med. Hum. Genet. 2012, 13, 45-62. [CrossRef]

18. Vyletal, P. Diversity of cystathionine $\beta$-synthase haplotypes bearing the most common homocystinuria mutation c. 833T> C: A possible role for gene conversion. Hum. Mutat. 2007, 28, 255-264.

19. Skovby, F.; Gaustadnes, M.; Mudd, S.H. A revisit to the natural history of homocystinuria due to cystathionine $\beta$-synthase deficiency. Mol. Genet. Metab. 2010, 99, 1-3. [CrossRef]

20. Sokolova, J. Cystathionine beta-synthase deficiency in Central Europe: Discrepancy between biochemical and molecular genetic screening for homocystinuric alleles. Hum. Mutat. 2001, 18, 548-549. [CrossRef]

21. Janošík, M. Birth prevalence of homocystinuria in Central Europe: Frequency and pathogenicity of mutation c. 1105C > T (p. R369C) in the cystathionine beta-synthase gene. J. Pediatr. 2009, 154, 431-437. [CrossRef]

22. Kožich, V. Analysis of CBS alleles in Czech and Slovak patients with homocystinuria: Report on three novel mutations E176K, W409X and 1223+ 37 de199. J. Inherit. Metab. Dis. 1997, 20, 363-366. [CrossRef]

23. Gallagher, P.M. High frequency (71\%) of cystathionine $\beta$-synthase mutation G307S in Irish homocystinuria patients. Hum. Mutat. 1995, 6, 177-180. [CrossRef] [PubMed]

24. Gupta, S. Mouse modeling and structural analysis of the p. G307S mutation in human cystathionine $\beta$-synthase (CBS) reveal effects on CBS activity but not stability. J. Biol. Chem. 2018, 293, 13921-13931. [CrossRef] [PubMed]

25. ClinVar. NM_000071.2(CBS):c.919G>A (p.Gly307Ser). 2019. Available online: https://www.ncbi.nlm.nih.gov/ clinvar/variation/117/ (accessed on 1 February 2020).

26. Franchis, R.D. Identical genotypes in siblings with different homocystinuric phenotypes: Identification of three mutations in cystathionine $\beta$-synthase using an improved bacterial expression system. Hum. Mol. Genet. 1994, 3, 1103-1108. [CrossRef] [PubMed]

27. De Franchis, R. Clinical aspects of cystathionine $\beta$-synthase deficiency: How wide is the spectrum? Eur. J. Pediatr. 1998, 157, S67-S70. [CrossRef] [PubMed]

28. de Franchis, R. Four novel mutations in the cystathionine $\beta$-synthase gene: Effect of a second linked mutation on the severity of the homocystinuric phenotype. Hum. Mutat. 1999, 13, 453-457. [CrossRef]

29. Sperandeo, M. Molecular analysis of patients affected by homocystinuria due to cystathionine $\beta$-synthase deficiency: Report of a new mutation in exon 8 and a deletion in intron 11. J. Inherit. Metab. Dis. 1995, 18, 211-214. [CrossRef]

30. Evangelisti, L. Vascular and connective tissue features in 5 Italian patients with homocystinuria. Int. J. Cardiol. 2009, 134, 251-254. [CrossRef]

31. Urreizti, R. The p. T191M mutation of the CBS gene is highly prevalent among homocystinuric patients from Spain, Portugal and South America. J. Hum. Genet. 2006, 51, 305. [CrossRef] 
32. Cozar, M. Identification and functional analyses of CBS alleles in Spanish and Argentinian homocystinuric patients. Hum. Mutat. 2011, 32, 835-842. [CrossRef]

33. Casique, L. Characterization of two pathogenic mutations in cystathionine beta-synthase: Different intracellular locations for wild-type and mutant proteins. Gene 2013, 531, 117-124. [CrossRef]

34. Aral, B. Two novel mutations (K384E and L539S) in the C-terminal moiety of the cystathionine ${ }^{2}$-synthase protein in two French pyridoxine-responsive homocystinuria patients. Hum. Mutat. 1997, 9, 81. [CrossRef]

35. Moat, S.J. The molecular basis of cystathionine $\beta$-synthase (CBS) deficiency in UK and US patients with homocystinuria. Hum. Mutat. 2004, 23, 206. [CrossRef] [PubMed]

36. Carmel, R.; Jacobsen, D.W. Homocysteine in Health and Disease; Cambridge University Press: Cambridge, UK, 2001.

37. Kluijtmans, L. Defective cystathionine beta-synthase regulation by S-adenosylmethionine in a partially pyridoxine responsive homocystinuria patient. J. Clin. Investig. 1996, 98, 285-289. [CrossRef] [PubMed]

38. Lloyd, M.S. Identical Twins with Crouzon Syndrome: Eight-Year Follow-up, Genetic Considerations, and Operative Management. Craniomaxillofacial Trauma Reconstr. 2017, 10, 286-291. [CrossRef]

39. Tröndle, U. Molecular and Clinical Characterisation of Homocystinuria in Two Austrian Families with Cystathionine $\beta$-Synthase Deficiency. Acta Medica Austriaca 2001, 28, 145-151. [CrossRef]

40. The Human Gene Mutation Database. Cystathionine-Beta-Synthase. 2019. Available online: http://www. hgmd.cf.ac.uk/ac/gene.php?gene=CBS (accessed on 25 January 2020).

41. Garland, J. Homocystinuria: Challenges in diagnosis and management. Paediatr. Child Health 1999, 4, 557-562. [CrossRef]

42. Poloni, S. CBS mutations are good predictors for B6-responsiveness: A study based on the analysis of 35 Brazilian Classical Homocystinuria patients. Mol. Genet. Genom. Med. 2018, 6, 160-170. [CrossRef]

43. Kelly, P. Stroke in young patients with hyperhomocysteinemia due to cystathionine beta-synthase deficiency. Neurology 2003, 60, 275-279. [CrossRef]

44. Kožich, V.; Kraus, J.P. Screening for mutations by expressing patient cDNA segments in E. coli: Homocystinuria due to cystathionine $\beta$-synthase deficiency. Hum. Mutat. 1992, 1, 113-123.

45. Sperandeo, M.P. A 68-bp insertion found in a homocystinuric patient is a common variant and is skipped by alternative splicing of the cystathionine beta-synthase mRNA. Am. J. Hum. Genet. 1996, 59, 1391.

46. Kruger, W.D.; Cox, D.R. A yeast assay for functional detection of mutations in the human cystathionine $\beta$-synthase gene. Hum. Mol. Genet. 1995, 4, 1155-1161. [CrossRef] [PubMed]

47. Magner, M. Vascular presentation of cystathionine beta-synthase deficiency in adulthood. J. Inherit. Metab. Dis. Off. J. Soc. Study Inborn Errors Metab. 2011, 34, 33-37. [CrossRef] [PubMed]

48. Wasim, M. Aminoacidopathies: Prevalence, etiology, screening, and treatment options. Biochem. Genet. 2018, 56, 7-21. [CrossRef] [PubMed]

49. CAGS. Homocystinuria; Centre for Arab Genomic Studies: Dubai, UAE, 2020.

50. Moammar, H. Incidence and patterns of inborn errors of metabolism in the Eastern Province of Saudi Arabia, 1983-2008. Ann. Saudi Med. 2010, 30, 271-277. [CrossRef] [PubMed]

51. Yadav, G. Aminoacidopathies among institutionalised mentally retarded in Kuwait. Clin. Genet. 1992, 42, 212. [CrossRef] [PubMed]

52. Zschocke, J. Molecular neonatal screening for homocystinuria in the Qatari population. Hum. Mutat. 2009, 30, 1021-1022. [CrossRef] [PubMed]

53. Gaustadnes, M. The molecular basis of cystathionine beta-synthase deficiency in Australian patients: Genotype-phenotype correlations and response to treatment. Hum. Mutat. 2002, 20, 117-126. [CrossRef]

54. Urreizti, R. Spectrum of CBS mutations in 16 homocystinuric patients from the Iberian Peninsula: High prevalence of T191M and absence of I278T or G307S. Hum. Mutat. 2003, 22, 103. [CrossRef]

55. Lee, S.J. Identification and functional analysis of cystathionine beta-synthase gene mutations in patients with homocystinuria. J. Hum. Genet. 2005, 50, 648-654. [CrossRef]

56. Gan-Schreier, H. Newborn population screening for classic homocystinuria by determination of total homocysteine from Guthrie cards. J. Pediatr. 2010, 156, 427-432. [CrossRef]

57. De Lucca, M.; Casique, L. Characterization of cystathionine beta-synthase gene mutations in homocystinuric Venezuelan patients: Identification of one novel mutation in exon 6. Mol. Genet. Metab. 2004, 81, 209-215. [CrossRef] [PubMed] 
58. El-Said, M.F. A common mutation in the CBS gene explains a high incidence of homocystinuria in the Qatari population. Hum. Mutat. 2006, 27, 719. [CrossRef] [PubMed]

59. Elsaid, M.F. Are heterocygotes for classical homocystinuria at risk of vitamin B12 and folic acid deficiency? Mol. Genet. Metab. 2007, 92, 100-103. [CrossRef] [PubMed]

60. Mandava, P. What is the Prevalence of Homocystinuria and Homocysteinemia? 2018. Available online: https://www.medscape.com/answers/1952251--115701/what-is-the-prevalence-of-homocystinuriaand-homocysteinemia (accessed on 10 February 2020).

61. Chamberlin, M.E. Methionine adenosyltransferase I/III deficiency: Novel mutations and clinical variations. Am. J. Hum. Genet. 2000, 66, 347-355. [CrossRef] [PubMed]

62. Ludolph, A.C. Functional and morphological deficits in late-treated patients with homocystinuria: A clinical, electrophysiologic and MRI study. Acta Neurol. Scand. 1991, 83, 161-165. [CrossRef]

63. Sarov, M. A case of homocystinuria due to CBS gene mutations revealed by cerebral venous thrombosis. J. Neurol. Sci. 2014, 336, 257-259. [CrossRef]

64. Gat-Yablonski, G. Homocystinuria in the Arab population of Israel: Identification of two novel mutations using DGGE analysis. Hum. Mutat. 2000, 16, 372. [CrossRef]

65. Ibrahim, S. CBS mutations and MTFHR SNPs causative of hyperhomocysteinemia in Pakistani children. Mol. Boil. Rep. 2018, 45, 353-360. [CrossRef]

66. Schiff, M.; Blom, H.J. Treatment of inherited homocystinurias. Neuropediatrics 2012, 43, 295.

67. Gupta, S. Analysis of the Qatari R336C Cystathionine $\beta$-Synthase Protein in Mice. J. Inherit. Metab. Dis. 2019, 42, 831-838. [CrossRef]

68. Al-Dewik, N. Natural history, with clinical, biochemical, and molecular characterization of classical homocystinuria in the Qatari population. J. Inherit. Metab. Dis. 2019, 42, 813-830. [CrossRef] [PubMed]

69. Carson, N.A.; Neill, D. Metabolic abnormalities detected in a survey of mentally backward individuals in Northern Ireland. Arch. Dis. Child. 1962, 37, 505. [CrossRef] [PubMed]

70. Mudd, S.H. Homocystinuria: An enzymatic defect. Liver 1964, 1, 1. [CrossRef] [PubMed]

71. El Bashir, H. Neurodevelopmental and cognitive outcomes of classical homocystinuria: Experience from Qatar. In JIMD Reports; Springer: Berlin, Germany, 2014; Volume 21, pp. 89-95.

72. Zaidi, S. Clinical and molecular findings of 13 families from Saudi Arabia and a family from Sudan with homocystinuria. Clin. Genet. 2012, 81, 563-570. [CrossRef]

73. Pathare, A. Hereditary thrombophilia in ethnic Omani patients. Am. J. Hematol. 2006, 81, 101-106. [CrossRef]

74. Al Essa, M.; Rashed, M.; Ozand, P. Classic homocystinuria: Clinical, biochemical and radiological observations, and therapeutic outcome of 24 Saudi patients. EMHJ East. Mediterr. Health J. 1999, 5, 1196-1203.

75. Mahmud, I. Decoding the Metabolome and Lipidome of Child. Malnutrition by Mass Spectrometric Techniques: Present Status and Future Perspectives. Anal. Chem. 2019, 91, 14784-14791. [CrossRef]

76. Homocystinuria. Public Awareness of Homocystinuria. 2014. Available online: https://homocystinuria. wordpress.com/ (accessed on 12 February 2020).

77. Longhi, R.C. Cystathionine $\beta$-synthase deficiency: A qualitative abnormality of the deficient enzyme modified by vitamin B 6 therapy. Pediatr. Res. 1977, 11, 100. [CrossRef]

78. Cortez, L.; Sim, V. The therapeutic potential of chemical chaperones in protein folding diseases. Prion 2014, 8, 197-202. [CrossRef]

79. Tao, Y.-X.; Conn, P.M. Pharmacoperones as novel therapeutics for diverse protein conformational diseases. Physiol. Rev. 2018, 98, 697-725. [CrossRef]

80. Kopecka, J. Restoring assembly and activity of cystathionine beta-synthase mutants by ligands and chemical chaperones. J. Inherit. Metab. Dis. 2011, 34, 39-48. [CrossRef] [PubMed]

81. Uppala, J.K.; Gani, A.R.; Ramaiah, K.V. Chemical chaperone, TUDCA unlike PBA, mitigates protein aggregation efficiently and resists ER and non-ER stress induced HepG2 cell death. Sci. Rep. 2017, 7, 3831. [CrossRef] [PubMed]

82. Vang, S. The unexpected uses of urso-and tauroursodeoxycholic acid in the treatment of non-liver diseases. Glob. Adv. Health Med. 2014, 3, 58-69. [CrossRef] [PubMed]

83. Takai, N.; Narahara, H. Preclinical studies of chemotherapy using histone deacetylase inhibitors in endometrial cancer. Obstet. Gynecol. Int. 2010, 2010, 8. [CrossRef]

84. Wilcken, D.E.; Dudman, N.P.; Tyrrell, P.A. Homocystinuria due to cystathionine $\beta$-synthase deficiency-The effects of betaine treatment in pyridoxine-responsive patients. Metabolism 1985, 34, 1115-1121. [CrossRef] 
85. Bublil, E.M. Enzyme replacement with PEGylated cystathionine beta-synthase ameliorates homocystinuria in murine model. J. Clin. Investig. 2016, 126, 2372-2384. [CrossRef]

86. Gupta, S. Correction of cystathionine beta-synthase deficiency in mice by treatment with proteasome inhibitors. Hum. Mutat. 2013, 34, 1085-1093. [CrossRef]

87. Singh, L.R. Activation of mutant enzyme function in vivo by proteasome inhibitors and treatments that induce Hsp70. PLoS Genet. 2010, 6, e1000807. [CrossRef]

88. Gallego-Villar, L. Cysteamine revisited: Repair of arginine to cysteine mutations. J. Inherit. Metab. Dis. 2017, 40, 555-567. [CrossRef]

89. Majtan, T.; Pey, A.L.; Kraus, J.P. Kinetic stability of cystathionine beta-synthase can be modulated by structural analogs of S-adenosylmethionine: Potential approach to pharmacological chaperone therapy for homocystinuria. Biochimie 2016, 126, 6-13. [CrossRef]

90. Pey, A.L. Human cystathionine $\beta$-synthase (CBS) contains two classes of binding sites for S-adenosylmethionine (SAM): Complex. regulation of CBS activity and stability by SAM. Biochem. J. 2013, 449, 109-121. [CrossRef] [PubMed]

91. Wang, L. Modulation of cystathionine $\beta$-synthase level regulates total serum homocysteine in mice. Circ. Res. 2004, 94, 1318-1324. [CrossRef] [PubMed]

92. Lee, H.-O. Treatment of Cystathionine $\beta$-Synthase Deficiency in Mice Using a Minicircle-Based Naked DNA Vector. Hum. Gene Ther. 2019, 30, 1093-1100. [CrossRef] [PubMed]

(C) 2020 by the authors. Licensee MDPI, Basel, Switzerland. This article is an open access article distributed under the terms and conditions of the Creative Commons Attribution (CC BY) license (http://creativecommons.org/licenses/by/4.0/). 